\section{Kidney \\ Blood Pressure Research}

\title{
Effect of Lanthanum Carbonate on All- Cause Mortality in Patients Receiving Maintenance Hemodialysis: a Meta- Analysis of Randomized Controlled Trials
}

\author{
Fang Wang Xiangxue Lu $^{\mathrm{b}} \quad$ Jingli Zhang ${ }^{\mathrm{b}}$ Ruifang Xiong ${ }^{\mathrm{b}}$ Han Lib \\ Shixiang Wang \\ aDepartment of Hematology, The First Affiliated Hospital of Zhengzhou University, Zhengzhou, Henan \\ Province; 'bepartment of Blood Purification, Beijing Chao-Yang Hospital, Capital Medical University, \\ Beijing, China
}

\section{Key Words}

Lanthanum carbonate $\cdot$ Hyperphosphatemia $\cdot$ Hemodialysis $・$ All-cause mortality

\begin{abstract}
Background/Aims: Hyperphosphatemia is common in patients on hemodialysis. The efficacy of lanthanum carbonate (LC) in the treatment of hyperphosphatemia in these patients remains controversial. The objective of this meta-analysis was to evaluate the effect of LC on all-cause mortality in patients on maintenance hemodialysis. Methods: We electronically searched the PubMed, EMBASE, and Cochrane Library databases for all randomized controlled trials (RCTs) comparing LC with other phosphate binders used in adult hemodialysis patients, including calcium carbonate, calcium acetate, and sevelamer. Results: Nine RCTs involving 2813 patients were suitable for inclusion. Our results showed that all-cause mortality was significantly lower in patients who received LC than in those who received standard therapy (odds ratio [OR]: $0.45,95 \%$ confidence interval $[C I]: 0.32-0.63, P<0.00001)$. Compared with the controls, patients who received LC had significantly lower serum calcium and higher serum intact parathyroid hormone levels. However, there was no significant difference between the groups in the cardiovascular event rate (OR: $0.58,95 \% \mathrm{CI}: 0.31-1.06, P=0.07)$ or in serum phosphorus levels. Conclusion: Compared with standard therapy, LC reduced all-cause mortality in patients on hemodialysis but did not decrease the risk of cardiovascular events. The decrease in serum phosphorus level was similar between LC and the other phosphate binders, but the risk of hypercalcemia was lower in patients who received LC.

F. Wang, X. Lu and J. Zhang contributed equally to this work.

\begin{tabular}{ll}
\hline Prof. Han Li & Department of Blood Purification, Beijing Chao-Yang Hospital, Capital Medical University, \\
& No. 8 Gongti South Road, Chaoyang District, Beijing 100020 (China) \\
Tel. +8610 65935007, E-Mail hanli@ccmu.edu.cn
\end{tabular}
\end{abstract}




\section{Kidney \\ Blood Pressure Research}

Kidney Blood Press Res 2018;43:536-544

\begin{tabular}{l|l}
\hline DOI: $10.1159 / 000488700$ & (C) 2018 The Author(s). Published by S. Karger AG, Base
\end{tabular}

Published online: 6 April, 2018

www.karger.com/kbr

Wang et al.: Lanthanum Carbonate and Mortality in Hemodialysis Patients

\section{Introduction}

The morbidity of end-stage renal disease (ESRD) is increasing with years, in addition to the primary kidney disease, secondary kidney diseases, such as diabetic nephropathy, hypertensive nephropathy and multiple myeloma nephropathy are also important causes of ESRD. Hemodialysis is the main treatment for ESRD. However, hemodialysis has a limited ability to remove phosphorus, so hyperphosphatemia is a universal complication in patients receiving this treatment [1]. There is much evidence that high serum phosphorus levels contribute to cardiovascular damage, secondary hyperparathyroidism, and soft tissue calcification [2]. In addition to restricting dietary phosphorus intake, use of oral phosphate binders is important to reduce the serum phosphorus level.

A number of phosphate binders are available and are widely used in patients on hemodialysis [3]. However, which phosphate binder is best is still controversial for the following reasons: aluminum-based salts have toxic effects that can lead to serious hematological, neurological, and skeletal adverse events [4]; calcium-based phosphate binders can cause hypercalcemia and vascular calcification [5, 6]; magnesium-based salts have more gastrointestinal side effects and lower efficacy [7]; and sevelamer hydrochloride has the potential to decrease serum bicarbonate levels [8].

Lanthanum carbonate (LC), which does not contain aluminum or calcium, was approved for the management of serum phosphate levels in hemodialysis patients several years ago. Many studies have since confirmed that LC is highly effective for this purpose, but it remains unclear whether LC is better than other phosphate binders. The aim of this meta-analysis was to compare the efficacy of LC with that of other phosphate binders in hemodialysis patients.

\section{Materials and Methods}

\section{Inclusion criteria}

All randomized controlled trials (RCTs) that compared LC with other phosphate binders, including calcium carbonate, calcium acetate, sevelamer, and magnesium-containing or aluminum-containing phosphate binders, in adult hemodialysis patients (aged $\geq 18$ years) were included. The main outcomes were all-cause mortality, cardiovascular events, and serum phosphate, calcium, and intact parathyroid hormone (iPTH) levels.

\section{Search strategy}

Two authors electronically searched the PubMed, EMBASE, and Cochrane Library databases updated to April 22, 2017 using the terms "hemodialysis", "lanthanum carbonate", and "Fosrenol". No restrictions on language or year of publication were imposed. The reference lists of all identified studies were scanned for more potentially eligible studies.

\section{Data extraction}

All relevant data obtained by the search strategy were screened and extracted by 2 investigators working independently. Information on authorship, year of publication, country of origin, sample size, agent used in the control group, outcomes, and duration of follow-up was extracted from the included studies. The original authors were contacted by email if data were not available.

Quality assessment

Two reviewers independently assessed the risk of bias for each study using the criteria in the Cochrane Handbook version 5.0.1. Disagreement was resolved by discussion until consensus was reached. Each study was assessed for methodological quality, which included sequence generation, allocation concealment, and blinding method used, as well as potential sources of bias, including incomplete and selective reporting of outcomes. 


\section{Kidney Blood Pressure Research}

\section{Statistical analysis}

The statistical analysis was performed using Review Manager 5.3 (The Cochrane Collaboration, Copenhagen, Denmark). The $I^{2}$ statistic was used to estimate the heterogeneity between studies. For studies with $I^{2} \geq 50 \%$ and $P<0.1$, heterogeneity was considered significant and so a random-effects model was used. If there was no significant heterogeneity, a fixed-effects model was used. The results are expressed as the weighted mean difference (WMD) for continuous variables and as the odd ratio (OR) for dichotomous outcomes, both with the $95 \%$ confidence interval (CI). A $P$-value $<0.05$ was considered statistically significant. A funnel plot was used to evaluate potential publication bias.

\section{Results}

\section{Study selection}

In total, 746 studies were identified using the above-mentioned search strategy, 9 [9-17] of which were eligible for inclusion in our meta-analysis. Together, these 9 studies involved 2813 patients. Two hundred studies were excluded because of duplication, 498 based on the titles and abstracts, 28 because of ineligible comparisons, and 11 because the patients were undergoing peritoneal dialysis (Fig. 1).

\section{Characteristics of included studies}

The study characteristics are shown in Table 1 . Three studies $[13,16,17]$ compared an LC group with a control group using older phosphate binders (mainly calcium carbonate, calcium acetate, and sevelamer). The other 6 studies $[9-12,14,15]$ compared LC and calcium carbonate. All 9 studies were parallel RCTs.

\section{Quality of the studies}

Quality assessment for the 9 studies is shown in Table 2. We assigned "Yes" for a low risk of bias, "Unclear" for an uncertain risk of bias, and "No" for a high risk of bias according to the quality assessment instrument in the Cochrane Handbook version 5.0.1.

\section{Outcome measures}

All-cause mortality. Six studies [9$11,13,16,17]$ with data available for all-cause mortality were included in the analysis. There were 56 deaths in the LC group ( $n=869)$ and 115 deaths in the control group $(n=861)$. The all-cause mortality was significantly lower in the LC group than in the control group (OR: $0.45,95 \%$ CI: $0.32-0.63, \quad P<0.00001)$, with no significant heterogeneity $\left(I^{2}=0 \%\right.$, $P=0.45$; Fig. 2a).

Cardiovascular events. The most common cardiovascular events were arrhythmia, hypotension, angina pectoris, and edema. Four studies $[9,10,15,16]$ that reported the incidence of cardiovascular events were included in the analysis. There was no significant difference in the

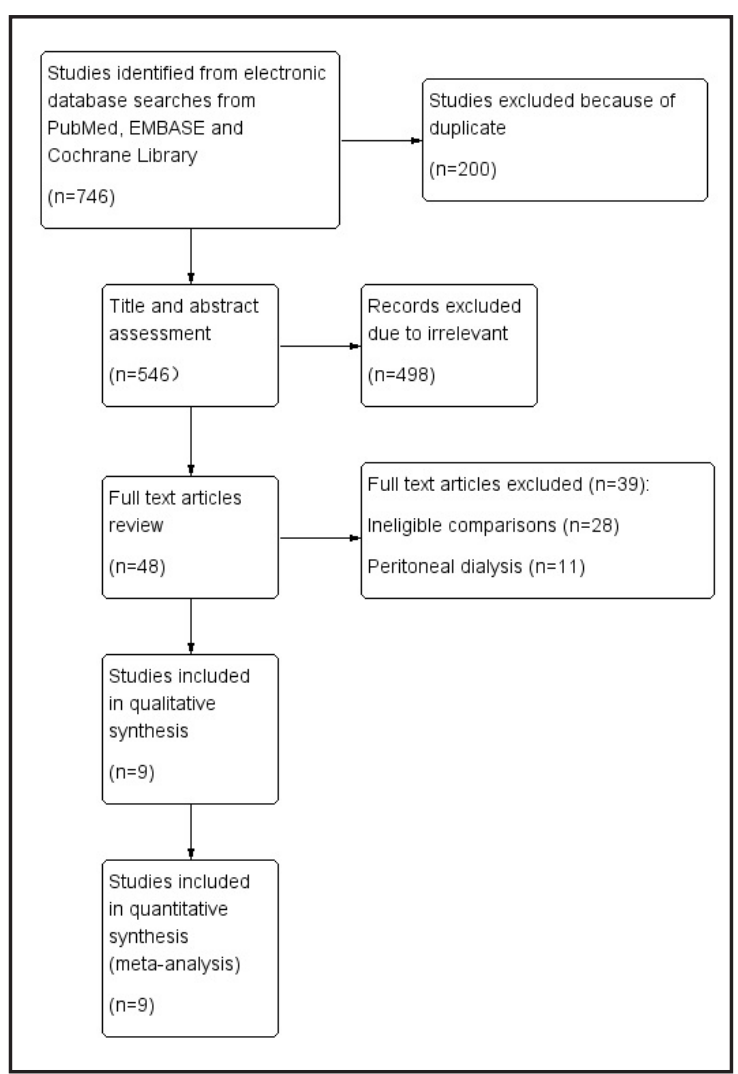

Fig. 1. Flow diagram of study selection process. 


\section{Kidney Blood Pressure Research}

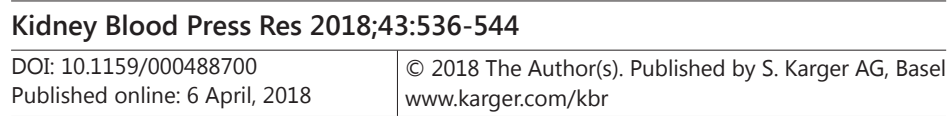
www.karger.com/kb

Table 1. Characteristics of included studies. *Outcomes, including (a) all-cause mortality, (b) cardiovascular events, and serum (c) phosphate, (d) calcium, and (e) intact parathyroid hormone levels. LC, lanthanum carbonate

\begin{tabular}{|c|c|c|c|c|c|c|}
\hline Study & Country & $\begin{array}{r}\text { Sample size } \\
\text { (LC/control) }\end{array}$ & $\begin{array}{c}\text { Mean age, years } \\
\text { (LC/control) }\end{array}$ & Drug used in control group & Outcomes* & Follow-up \\
\hline Toussaint 2011 & Australia & $22 / 23$ & $\begin{array}{r}56.0 \pm 15.2 / \\
58.8 \pm 14.9\end{array}$ & Calcium carbonate & $a, b, c$ & 18 months \\
\hline Ohtake 2013 & Japan & $26 / 26$ & $67.8 \pm 6.3$ & Calcium carbonate & $a, b, c, d, e$ & 6 months \\
\hline Wada 2014 & Japan & $21 / 22$ & $\begin{array}{c}65.6 \pm 10.2 / \\
65.8 \pm 8.5\end{array}$ & Calcium carbonate & $\mathrm{a}, \mathrm{c}, \mathrm{d}$ & 12 months \\
\hline Shigematsu 2008 & Japan & $126 / 132$ & $\begin{array}{r}58.8 \pm 10.5 / \\
56.1 \pm 11.5\end{array}$ & Calcium carbonate & $c, d, e$ & 8 weeks \\
\hline Kalil 2012 & USA & $10 / 10$ & $\begin{array}{c}65.0 \pm 9.0 / \\
68.0 \pm 9.0\end{array}$ & $\begin{array}{l}\text { Calcium acetate/ } \\
\text { sevelamer }\end{array}$ & $\mathrm{a}, \mathrm{c}, \mathrm{d}, \mathrm{e}$ & 12 months \\
\hline Chang 2016 & China & $13 / 12$ & $\begin{array}{c}56.6 \pm 11.5 / \\
61.2 \pm 7.8\end{array}$ & Calcium carbonate & $c, d, e$ & 24 weeks \\
\hline Hutchison 2005 & UK & $533 / 267$ & $\begin{array}{c}57.0 \pm 14.3 / \\
58.4 \pm 13.4\end{array}$ & Calcium carbonate & $\mathrm{b}$ & 6 months \\
\hline Finn 2006 & USA & $682 / 677$ & $\begin{array}{r}53.8 \pm 14.6 / \\
54.9 \pm 14.4\end{array}$ & $\begin{array}{c}\text { Calcium carbonate/calcium } \\
\text { acetate/sevelamer }\end{array}$ & $\mathrm{a}, \mathrm{b}$ & 2 years \\
\hline Malluche 2008 & USA & $108 / 103$ & $\begin{array}{l}48.5 \pm 13.4 / \\
50.6 \pm 13.9\end{array}$ & $\begin{array}{c}\text { Calcium carbonate/Calcium } \\
\text { acetate/Sevelamer }\end{array}$ & $\mathrm{a}$ & 2 years \\
\hline
\end{tabular}

Table 2. Quality assessment of included studies

\begin{tabular}{|c|c|c|c|c|c|c|}
\hline Study & $\begin{array}{l}\text { Sequence } \\
\text { generation }\end{array}$ & $\begin{array}{c}\text { Allocation } \\
\text { concealment }\end{array}$ & Blinding & $\begin{array}{c}\text { Incomplete } \\
\text { outcome data }\end{array}$ & $\begin{array}{l}\text { Selective } \\
\text { outcome } \\
\text { reporting }\end{array}$ & Other \\
\hline Toussaint 2011 & $\begin{array}{l}\text { Computer } \\
\text { generated }\end{array}$ & Yes & Single-blind & Yes & Yes & Unclear \\
\hline Ohtake 2013 & Unclear & Yes & Single-blind & Yes & Yes & Unclear \\
\hline Wada 2014 & Unclear & Unclear & Unclear & Yes & Yes & Unclear \\
\hline Shigematsu 2008 & Unclear & Unclear & Double-blind & Unclear & Yes & Unclear \\
\hline Kalil 2012 & Unclear & Unclear & Single-blind & Yes & Yes & Unclear \\
\hline Chang 2016 & Unclear & Unclear & Unclear & Yes & Yes & Unclear \\
\hline Hutchison 2005 & Unclear & Unclear & Unclear & Yes & Yes & Unclear \\
\hline Finn 2006 & Unclear & Unclear & Unclear & Yes & Yes & Unclear \\
\hline Malluche 2008 & Unclear & Unclear & Unclear & Yes & Yes & Unclear \\
\hline
\end{tabular}

cardiovascular event rate between the LC group and the control group (OR: 0.58, 95\% CI: $0.31-1.06, P=0.07)$, with significant heterogeneity $\left(I^{2}=64 \%, P=0.04\right.$; Fig. $\left.2 \mathrm{~b}\right)$.

Serum phosphorus. Data from 6 studies [9-14] could be included in the analysis. There was no significant difference in the serum phosphorus level between the LC group and the control group (WMD: $0.10,95 \% \mathrm{CI}:-0.14,0.33, P=0.44$ ), with no significant heterogeneity $\left(I^{2}=17 \%, P=0.30\right.$; Fig. 3a).

Serum calcium. Five studies [10-14] were included in this analysis. Serum calcium level was significantly lower in the LC group than in the control group (WMD: $-0.53,95 \% \mathrm{CI}:-0.67$, $-0.39, P<0.00001)$, with no significant heterogeneity $\left(I^{2}=0 \%, P=0.72\right.$; Fig. $\left.3 \mathrm{~b}\right)$.

Serum iPTH levels. Four studies $[10,12-14]$ were included in the analysis. Serum iPTH level was significantly higher in the LC group than in the control group (WMD: 68.94, 95\% CI: 34.55-103.33, $P<0.0001)$, with no significant heterogeneity $\left(I^{2}=0 \%, P=0.73\right.$; Fig. 3c $)$. 


\section{Kidney Bloód Pressure Research}

Publication bias. We examined a funnel plot using serum calcium level as an outcome. The plot was roughly symmetrical (Fig. 4) in that all scatters were substantially symmetrical and basically fell within the confidence limits, but were mostly distributed in the upper funnel plot, indicating no significant publication bias.

Fig. 2. Forest plots for all-cause mortality and cardiovascular events. (a) Allcause mortality is significantly lower in the LC group than in the control group. (b) No significant difference in cardiovascular events is seen between the LC and the control groups. LC, lanthanum carbonate.

Fig. 3. Forest plots for serum phosphate, calcium, and intact parathyroid hormone levels. (a) No significant difference in serum phosphate level is seen between the LC group and the control group. (b) Serum calcium level is significantly lower in the LC group than in the control group. (c) Serum parathyroid hormone level is significantly higher in the LC group than in the control group. LC, lanthanum carbonate.
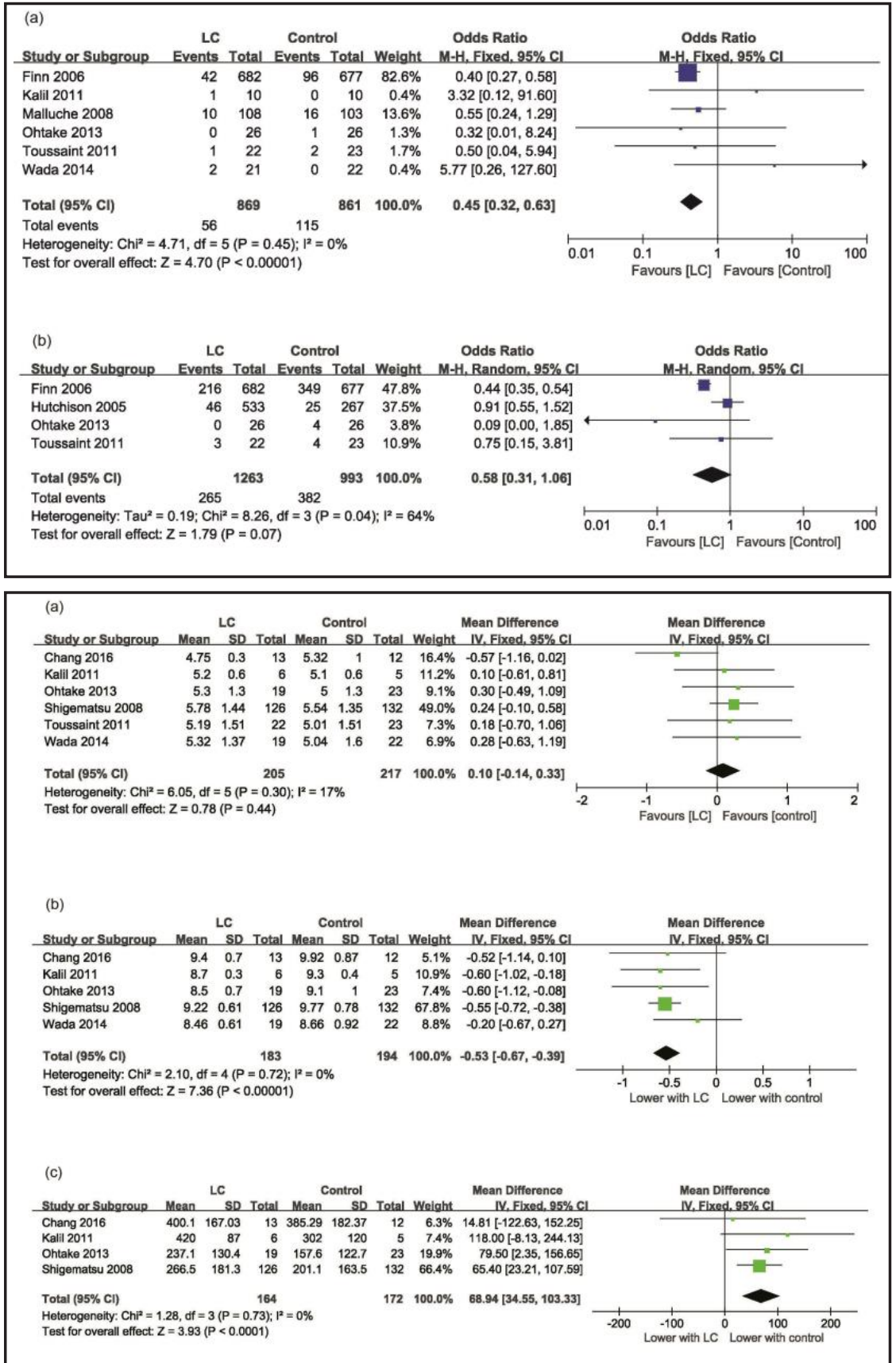


\section{Kidney Bloód Pressure Research}

\section{Discussion}

The results of this meta-analysis suggest that LC could achieve a greater reduction in allcause mortality compared with standard therapy, mainly including calcium carbonate, calcium acetate, and sevelamer, in patients on hemodialysis. There was also a tendency for reduction of the risk of cardiovascular events on LC, but this did not reach statistical significance. Interestingly, we also found that the serum calcium level was lower and serum iPTH level was higher in patients receiving LC than in those receiving standard therapy. No difference in serum phosphorus level was observed between LC and other phosphate binders.

Chronic kidney disease is a global health problem [18], and hemodialysis is the primary treatment in patients with ESRD [19]. However, hemodialysis has some drawbacks, and electrolyte disorders such as hyperphosphatemia are common in patients on this treatment [20]. It has been reported that increased serum phosphate levels are independently associated with increased morbidity and mortality in patients on hemodialysis $[21,22]$. Use of oral phosphate binders is important for reducing the serum phosphate level [23]. In the past, carbonate, calcium acetate, and sevelamer were often used for this purpose, but with unsatisfactory results. LC, a novel aluminum-free, calcium-free phosphate binder with low oral bioavailability of lanthanum [24] dissociates in the upper gastrointestinal tract after oral administration and binds phosphate released from food [25]. Several studies have demonstrated the therapeutic effect of LC on hyperphosphatemia [26, 27]. A previous systematic review conducted by Jamal et al. demonstrated a $22 \%$ reduction in all-cause mortality in patients receiving non-calcium-based phosphate binders (mainly sevelamer) when compared with those who receiving calcium-based phosphate binders [28]. Another meta-analysis by Zhai et al. found no statistically significant difference in all-cause mortality between patients on peritoneal dialysis or hemodialysis who were receiving LC and their counterparts receiving calcium-based phosphate binders [29]. However, the efficacy of LC has been inconclusive.

In our meta-analysis, we compared the all-cause mortality as well as other parameters, including cardiovascular events and serum phosphate, calcium, and iPTH levels, between patients on hemodialysis receiving LC and those receiving standard therapy for the first time. The meta-analysis included 9 studies in 2813 patients. Only 6 studies reported on deaths that occurred during the study period and the duration of follow-up ranged from 6 months to 2 years. Our findings indicate that LC had a more beneficial effect on all-cause mortality than standard therapy with no significant heterogeneity. Comparing the reduction in cardiovascular event rates between the groups, there was a tendency toward statistical significance $(P=0.07)$ in the LC group. The mechanism by which LC might reduce all-cause mortality is controversial. One potential explanation for the decreased mortality in the LC group might be related to slowing of vascular calcification. Several RCTs have showed that use of calcium-based phosphate binders was associated with greater vascular calcification than non-calcium-based binders [6]. A previous review showed that the incidence of 


\section{Kidney \\ Blood Pressure Research}

hypercalcemia was lower with LC than with calcium-based phosphate binders [29]. Behets et al. [30] found that LC could reduce net calcium absorption to a greater extent than sevelamer. Similarly, our meta-analysis found that the serum calcium level was lower in the LC group with no significant heterogeneity. Filiopoulos et al. [31] compared sevelamer hydrochloride and LC in patients on hemodialysis and found a beneficial effect of switching from sevelamer hydrochloride to LC in terms of reducing metabolic acidosis and hyperkalemia. Moreover, several studies have shown that switching from sevelamer to LC could reduce drug costs and tablet burden while maintaining serum phosphate levels within the normal range [32,33]. Unfortunately, there were not enough RCTs available to compare these parameters between the various phosphate binders individually. In our meta-analysis, we found no significant difference in the serum phosphate level, but the serum iPTH level was higher in the LC group with no significant heterogeneity. Previous studies have shown that a lower serum iPTH level was common in patients with the adynamic bone disorder generally associated with overuse of calcium-based phosphate binders [34]. This suggests that LC might prevent oversuppression of iPTH secretion and have a beneficial effect on adynamic bone disorder and vascular calcification.

Although this meta-analysis yielded promising results, some limitations need to be taken into consideration. First, it included 9 RCTs, 6 of which compared LC with calcium carbonate and 3 of which compared an LC group with a control group using other phosphate binders, mainly including calcium carbonate, calcium acetate, and sevelamer, so it was difficult to compare the effects of LC with those of other phosphate binders individually. Second, the number of studies was small, the number of study participants in each trial was also small, and the methodological quality of the trials was variable, all of which limit our ability to draw any definitive conclusions.

\section{Conclusion}

Compared with standard therapy, LC reduces all-cause mortality but not the risk of cardiovascular events in patients on hemodialysis. LC and the other phosphate binders decreased serum phosphate levels to a similar extent, but LC also decreased the risk of hypercalcemia.

\section{Acknowledgements}

This work was supported by the National Natural Science Foundation of China (81670673) and Beijing Natural Science Foundation (7182060).

\section{Disclosure Statement}

The authors declare no conflict of interest.

\section{References}

1 Huml AM, Sullivan CM, Leon JB, Sehgal AR: The adequacy of phosphorus binder prescriptions among American hemodialysis patients. Ren Fail 2012;34:1258-1263.

2 Floege J: Phosphate binders in chronic kidney disease: a systematic review of recent data. J Nephrol 2016;29:329-340. 


\section{Kidney \\ Blood Pressure Research}

\begin{tabular}{l|l}
\hline Kidney Blood Press Res 2018;43:536-544 \\
\hline DOI: 10.1159/000488700 & $\begin{array}{l}\text { (c) } 2018 \text { The Author(s). Published by S. Karger AG, Basel } \\
\text { www.karger.com/kbr }\end{array}$ \\
$\begin{array}{ll}\text { Published onlIne: 6 April, } 2018 & \end{array}$
\end{tabular}

3 Locatelli F, Del Vecchio L, Violo L, Pontoriero G: Phosphate binders for the treatment of hyperphosphatemia in chronic kidney disease patients on dialysis: a comparison of safety profiles. Expert Opin Drug Saf 2014;13:551-561.

4 Marcuccilli M, Chonchol M, Jovanovich A: Phosphate Binders and Targets Over Decades: Do We have it Right Now? Semin Dial 2017;30:134-141.

5 Block GA, Wheeler DC, Persky MS, Kestenbaum B, Ketteler M, Spiegel DM, Allison MA, Asplin J, Smits G, Hoofnagle AN, Kooienga L, Thadhani R, Mannstadt M, Wolf M, Chertow GM: Effects of phosphate binders in moderate CKD. J Am Soc Nephrol 2012;23:1407-1415.

-6 West SL, Swan VJ, Jamal SA: Effects of calcium on cardiovascular events in patients with kidney disease and in a healthy population. Clin J Am Soc Nephrol 2010;5:S41-47.

7 Barreto FC, de Oliveira RA, Oliveira RB, Jorgetti V: Pharmacotherapy of chronic kidney disease and mineral bone disorder. Expert Opin Pharmacother 2011;12:2627-2640.

8 Pai AB, Shepler BM: Comparison of sevelamer hydrochloride and sevelamer carbonate: risk of metabolic acidosis and clinical implications. Pharmacotherapy 2009;29:554-561.

-9 Toussaint ND, Lau KK, Polkinghorne KR, Kerr PG: Attenuation of aortic calcification with lanthanum carbonate versus calcium-based phosphate binders in haemodialysis: A pilot randomized controlled trial. Nephrology (Carlton) 2011;16:290-298.

10 Ohtake T, Kobayashi S, Oka M, Furuya R, Iwagami M, Tsutsumi D, Mochida Y, Maesato K, Ishioka K, Moriya H, Hidaka S: Lanthanum carbonate delays progression of coronary artery calcification compared with calcium-based phosphate binders in patients on hemodialysis: a pilot study. J Cardiovasc Pharmacol Ther 2013;18:439-446.

11 Wada K, Wada Y: Evaluation of aortic calcification with lanthanum carbonate vs. calcium-based phosphate binders in maintenance hemodialysis patients with type 2 diabetes mellitus: an open-label randomized controlled trial. Ther Apher Dial 2014;18:353-360.

12 Shigematsu T: Multicenter prospective randomized, double-blind comparative study between lanthanum carbonate and calcium carbonate as phosphate binders in Japanese hemodialysis patients with hyperphosphatemia. Clin Nephrol 2008;70:404-410.

-13 Kalil RS, Flanigan M, Stanford W, Haynes WG: Dissociation between progression of coronary artery calcification and endothelial function in hemodialysis patients: a prospective pilot study. Clin Nephrol 2012;78:1-9.

14 Chang YM, Tsai SC, Shiao CC, Liou HH, Yang CL, Tung NY, Hsu KS, Chen IL, Liu MC, Kao JL, Jhen RN, Huang YT: Effects of lanthanum carbonate and calcium carbonate on fibroblast growth factor 23 and hepcidin levels in chronic hemodialysis patients. Clin Exp Nephrol 2017;1:908-916.

15 Hutchison AJ, Maes B, Vanwalleghem J, Asmus G, Mohamed E, Schmieder R, Backs W, Jamar R, Vosskuhler A: Efficacy, tolerability, and safety of lanthanum carbonate in hyperphosphatemia: a 6-month, randomized, comparative trial versus calcium carbonate. Nephron Clin Pract 2005;100:c8-19.

-16 Finn WF: Lanthanum carbonate versus standard therapy for the treatment of hyperphosphatemia: safety and efficacy in chronic maintenance hemodialysis patients. Clin Nephrol 2006;65:191-202.

17 Malluche HH, Siami GA, Swanepoel C, Wang GH, Mawad H, Confer S, Smith M, Pratt RD, Monier-Faugere MC: Improvements in renal osteodystrophy in patients treated with lanthanum carbonate for two years. Clin Nephrol 2008;70:284-295.

-18 Jha V, Garcia-Garcia G, Iseki K, Li Z, Naicker S, Plattner B, Saran R, Wang AY, Yang CW: Chronic kidney disease: global dimension and perspectives. Lancet 2013;382:260-272.

19 Thorsteinsdottir B, Swetz KM, Feely MA, Mueller PS, Williams AW: Are there alternatives to hemodialysis for the elderly patient with end-stage renal failure? Mayo Clin Proc 2012;87:514-516.

20 Collinson A, McMullan M, Tse WY, Sadler H: Managing serum phosphate in haemodialysis patients: time for an innovative approach? Eur J Clin Nutr 2014;68:392-396.

21 Block GA, Klassen PS, Lazarus JM, Ofsthun N, Lowrie EG, Chertow GM: Mineral metabolism, mortality, and morbidity in maintenance hemodialysis. J Am Soc Nephrol 2004;15:2208-2218.

-22 Tentori F, Blayney MJ, Albert JM, Gillespie BW, Kerr PG, Bommer J, Young EW, Akizawa T, Akiba T, Pisoni RL, Robinson BM, Port FK: Mortality risk for dialysis patients with different levels of serum calcium, phosphorus, and PTH: the Dialysis Outcomes and Practice Patterns Study (DOPPS). Am J Kidney Dis 2008;52:519-530. 


\section{Kidney \\ Blood Pressure Research}

Wang et al.: Lanthanum Carbonate and Mortality in Hemodialysis Patients

-23 Goldsmith D, Covic A: Oral phosphate binders in CKD - is calcium the (only) answer? Clin Nephrol 2014;81:389-395.

24 Damment SJ, Pennick M: Clinical pharmacokinetics of the phosphate binder lanthanum carbonate. Clin Pharmacokinet 2008;47:553-563.

-25 Yang Y, Shah RB, Yu LX, Khan MA: In vitro bioequivalence approach for a locally acting gastrointestinal drug: lanthanum carbonate. Mol Pharm 2013;10:544-550.

-26 Komaba H, Kakuta T, Suzuki H, Hida M, Suga T, Fukagawa M: Survival advantage of lanthanum carbonate for hemodialysis patients with uncontrolled hyperphosphatemia. Nephrol Dial Transplant 2015;30:107-114.

-27 Lee YK, Choi HY, Shin SK, Lee HY: Effect of lanthanum carbonate on phosphate control in continuous ambulatory peritoneal dialysis patients in Korea: a randomized prospective study. Clin Nephrol 2013;79:136-142.

28 Jamal SA, Vandermeer B, Raggi P, Mendelssohn DC, Chatterley T, Dorgan M, Lok CE, Fitchett D, Tsuyuki RT: Effect of calcium-based versus non-calcium-based phosphate binders on mortality in patients with chronic kidney disease: an updated systematic review and meta-analysis. Lancet 2013;382:1268-1277.

-29 Zhai CJ, Yu XS, Sun QL, Li L, Zhang LT, Zhou AY, Wang R: Effect of lanthanum carbonate versus calcium-based phosphate binders in dialysis patients: a meta-analysis. Clin Nephrol 2014;82:372-378.

-30 Behets GJ, Dams G, Damment SJ, Martin P, De Broe ME, D’Haese PC: Differences in gastrointestinal calcium absorption after the ingestion of calcium-free phosphate binders. Am J Physiol Renal Physiol 2014;306:F61-67.

-31 Filiopoulos V, Koutis I, Trompouki S, Hadjiyannakos D, Lazarou D, Vlassopoulos D: Lanthanum carbonate versus sevelamer hydrochloride: improvement of metabolic acidosis and hyperkalemia in hemodialysis patients. Ther Apher Dial 2011;15:20-27.

-32 Keith MS, Wilson RJ, Preston P, Copley JB: Cost-minimization analysis of lanthanum carbonate versus sevelamer hydrochloride in US patients with end-stage renal disease. Clin Ther 2014;36:1276-1286.

-33 Petrov MK, Dimitrova M, Petrova GI: Cost- Minimization Analysis Of the Direct Costs Of Sevelamer Carbonate And Lanthanum Carbonate In the Treatment Of Ckd-Nd Patients. Value Health 2014;17:A470.

34 Eddington H, Heaf JG: Clinical management of disturbances of calcium and phosphate metabolism in dialysis patients. NDT Plus 2009;2:267-272. 